\title{
La arquitectura moderna latinoamericana en pauta
}

\author{
FERNANDO VÁZQUEZ RAMOS ·Universidade São Judas Tadeu, Brasil·fernando@vi.arq.br
}

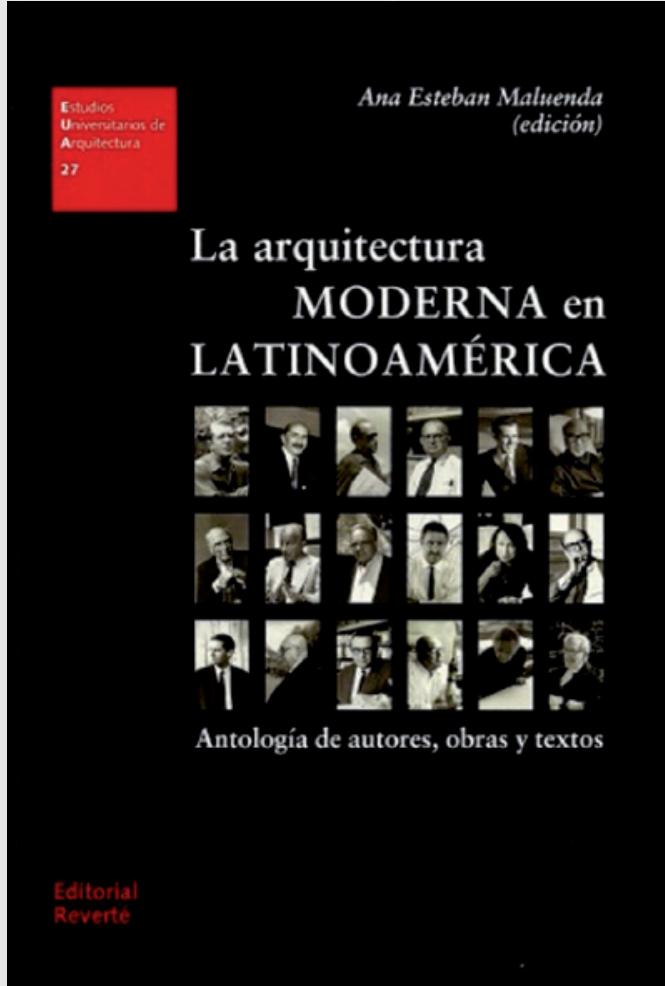

“LA ARQUITECTURA MODERNA EN LATINOAMÉRICA. Antología de autores, obras y textos" Ana Esteban Maluenda ${ }^{[1]}$ (ed.) · Barcelona: Reverté, 2016 a colección Estudios Universitarios de LArquitectura, producida por la editoria Reverté y dirigida por Jorge Sainz, un entusiasta promotor de la investigación en arquitectura, nos ofrece su último lanzamiento: LA ARQUITECTURA MODERNA EN LATINOAMÉRICA: ANTOLOGÍA DE AUTORES, OBRAS Y TEXTOS. El libro, pensado, organizado y editado por Ana Esteban Maluenda, reinstala un viejo tema, aunque con una presentación no tan usual: la antología.

Como toda antología, esta reúne pequeños textos con la finalidad de presentar un tema que, sin embargo, no pretende ser unitario, sino experimental y polivalente. Así, no se trata de realizar una simple recopilación, como subraya Ana Esteban Maluenda, sino que el propósito de la selección -de autores, obras y textos- es el de presentar un panorama de calidad documental, histórica y crítica.

Anthos-légein, origen griego de "antología", significa genéricamente "recoger flores", como nos recuerda Ana Esteban Maluenda. Légein es, con certeza, un verbo muy apropiado para definir la lógica analítica del libro, pues describe "la fuerza de producir tensiones y de integrar conflictos". Por otra parte, antología también se relaciona con logos, que no es otra cosa que el conocimiento en sí. Ambas, légein y logos, se confunden con "lenguaje", dándonos la pauta más precisa de qué tipo de libro tenemos en nuestras manos. En realidad, este volumen es un precioso mecanismo de conocimiento de las tensiones y conflictos que la producción de un tipo específico de arquitectura, la moderna, fue capaz de integrar y desarrollar como respuesta cultural, como lenguaje, en un espacio y tiempo preciso: América (Latina) entre 1930 y 1970.

O, si se quiere decir de forma más poética, este libro recoge algunas de las más bellas flores del enorme jardín que es nuestra América y las ofrece para su contemplación, y reflexión, a todos los que tengan la oportunidad de leerlo, a través de las estampas de los 18 arquitectos $^{[1]}$ de los que se ocupa: Alberto Cruz, Antonio Bonet, Carlos Raúl Villanueva, Claudio Caveri, Clorindo Testa, Eladio Dieste, Emilio Duhart, Félix Candela, Héctor Velarde, Juan O'Gorman, Lúcio Costa, Lina Bo Bardi, Luis Barragán, Mario Roberto Álvarez, Oscar Niemeyer, Pedro Ramírez Vázquez, Ricardo Porro y Rogelio Salmona.

Con toda la razón podría decirse que en esta lista faltan nombres, pues estos 18 artistas no pueden representar el complejo mundo americano que se vivió en esos 40 años, pero aquí debemos volver al sentido de légein como una narrativa, no como una taxonomía. E libro no pretende cerrar el tema, sino abrirlo al diálogo; y lo hace formulando una selección deliberada e intencionada -discutida y con finalidad- de algunos de los más sensibles y carismáticos artistas responsables de la apropiación, construcción y diseminación de la arquitectura moderna en nuestro continente.

\footnotetext{
11] Doctora (2008) y arquitecta (1996) por la Escuela Técnica Superior de Arquitectura de Madrid, España, profesora de la misma escuela, investigadora de la arquitectura del siglo XX y su difusión internacional, especialmente a través de las revistas. Fue redactora de las revistas AV Monografías y Arquitectura Viva.

[2] Aunque tres sean ingenieros.
} 
La propuesta editorial divide estos arquitectos en tres grupos. Los de una primera generación, es decir, los maestros que hasta la Segunda Guerra Mundial se encargaron de desenvolver, para América Latina, una retomada muy particular y creativa de los preceptos del movimiento moderno internacional (19301950): Barragán, Bonet, Costa, Niemeyer, O'Gorman y Villanueva. Después los arquitectos que consiguieron realizar una obra menos dependiente del influjo externo y más vinculada a las vicisitudes locales (con obras representativas construidas entre 1950-1960): Álvarez, Bo Bardi, Candela, Caveri, Dieste y Testa. Finalmente, un grupo que, de acuerdo con la editora, representa la madurez disciplinar, propia y autónoma, "resultado de la destilación perfecta de sus circunstancias particulares", que se consolida durante toda la década de 1960: Cruz, Duhart, Porro, Ramírez Vázquez, Salmona y Velarde.

Partiendo de una biografía -importante para el público menos especializado- cada capítulo se desarrolla a través de una breve reflexión, encomendada a críticos e historiadores especializados, donde se sitúa la producción de cada arquitecto en un contexto más amplio (cultural, social, económico y político), lo que permite al lector una comprensión integral de los temas abordados en cada caso y proporciona un amplio abanico de interpretaciones. Cada presentación se cierra con uno o varios textos escritos por el propio arquitecto.

Por otro lado, la calidad de los textos críticos resulta evidente. Así como los arquitectos seleccionados reflejan la consolidación de la arquitectura moderna en América Latina entre 1930 y 1970, el trabajo de estos intelectuales representa el excelente nivel de análisis y reflexión alcanzados en el continente al día de hoy.

Además, el libro nos ofrece un prólogo de Ramón Gutiérrez, con certeza uno de los más importantes historiadores de la arquitectura de América Latina en activo, que afirma que a través de este libro se consigue una inmersión en la "rica variedad de trayectorias" de los protagonistas de esta historia de 40 años, lo que termina revelando la "dialéctica que surge entre el discurso y la práctica profesional". La antología aborda la relación conflictiva entre la política y la arquitectura, el compromiso social y la naturaleza del arte, y de la arquitectura, que impregnan el trabajo de los profesionales estudiados. Sin duda, se trata de un texto muy rico que demuestra el profundo conocimiento de Gutiérrez sobre el tema y que, además, complementa y enriquece la contribución del resto de historiadores invitados.

Por último, Ana Esteban Maluenda remata el libro con un epílogo centrado en la historiografía moderna, donde revisita "lo que se ha dicho sobre" sobre la arquitectura en América Latina. Partiendo de los historiadores clásicos, la autora llega a los más recientes abordajes que resultan, no solo de "historias" como las de Frampton y Cohen, sino también de las publicaciones periódicas especializadas de todo el mundo. Un recorrido por la historia de la arquitectura, por la crítica y lo por lo que el mundo piensa sobre la arquitectura que se desarrolla en las Américas al sur del Río Bravo.

Por todas estas razones, la arquitectura moderna en Latinoamérica es una importante y bien estructurada puerta de entrada para el lector interesado en el surgimiento, desarrollo y consolidación de la arquitectura moderna en general y de la particular forma en que ese movimiento alcanzó en las Américas. 